\title{
Impact of Local Application of Clindamycin in Preventing Dry Socket after Third Mandibular Molar Extraction
}

\author{
Vjosa Hamiti-Krasniqi' ${ }^{1}$, Zana Agani2 ${ }^{*}$, Gafur Shtino ${ }^{3}$, Mergime Loxha ${ }^{4}$, Jehona Ahmedi², \\ Aida Rexhepi ${ }^{5}$ \\ ${ }^{1}$ Dental Clinic “Identity”, Prishtina, Kosova \\ ${ }^{2}$ Department of Oral Surgery, University Dentistry Clinical Center of Kosova, Prishtina, Kosovo \\ ${ }^{3}$ Department of Maxillofacial Surgery, Faculty of Medicine, University of Tirana, Tirana, Albania \\ ${ }^{4}$ Department of Maxillofacial Surgery, Clinical University Center of Kosova, Prishtina, Kosovo \\ ${ }^{5}$ Department of Pediatric Dentistry, University Dentistry Clinical Center of Kosova, Prishtina, Kosovo \\ Email: zana.agani@gmail.com
}

Received 6 July 2014; revised 23 August 2014; accepted 6 September 2014

Copyright (C) 2014 by authors and Scientific Research Publishing Inc.

This work is licensed under the Creative Commons Attribution International License (CC BY). http://creativecommons.org/licenses/by/4.0/

(c) (i) Open Access

\begin{abstract}
Extraction of third mandibular tooth is one of the most commonly performed surgical procedures in oral surgery. One of the most common complications following the extraction of third mandibular molar teeth is dry socket (alveolar osteitis). Dry socket is the delayed healing of the wound of the alveolar bone after dental extractions. The purpose of this study was to determine if the intra-alveolar application of Clindamycin could reduce the incidence of dry socket following the extraction of third mandibular molar tooth. Patients who qualified for the prospective, randomized, double-masked, placebo-controlled trial were randomly divided into 2 groups, each group 30 patients. The first group ( 30 patients) included smokers and the second group ( 30 patients) included non smokers. Both groups had the mandibular third molar extracted in both sides at the same time. In total, 120 third molars were extracted. The left site was a study group in which we applied the clindamycin and the right site was a control group. The patients were also divided by gender. Dry socket occurred in $3.3 \%$ of cases for patients whom were given Clindamycin, regardless of their smoking habits, as opposed to $31.7 \%$ for those who did not receive the antibiotic. Results clearly showed that Clindamycin had a huge impact on reducing dry socket regardless of smoking habits.
\end{abstract}

\section{Keywords}

Dry Socket, Clindamycin, Non-Smokers, Smokers

\footnotetext{
${ }^{*}$ Corresponding author.
}

How to cite this paper: Hamiti-Krasniqi, V., Agani, Z., Shtino, G., Loxha, M., Ahmedi, J. and Rexhepi, A. (2014) Impact of Local Application of Clindamycin in Preventing Dry Socket after Third Mandibular Molar Extraction. Open Journal of Stomatology, 4, 463-469. http://dx.doi.org/10.4236/ojst.2014.49062 


\section{Introduction}

Dry socket has been treated by many different authors for nearly 110 years and their research has resulted in numerous books published that address the problem from various angles. Their data indicates that reported cases of dry socket are within a wide range from $1 \%$ to $70 \%$ [1]. The author Testa is more precise and ranges from 0.5 to $68.4 \%$ [2]. In a general manner, it has been confirmed that dry socket most commonly appears after third molar extraction and premolars of the lower jaw. In case studies, we also encounter a wide range of occurrence, somewhere from $1 \%$ - 45\% [3]-[5], but most often mentioned somewhere in $20 \%$ - 30\% of cases [6]. Regarding gender, the majority of studies support the indication that females, even without oral contraceptives, have a greater tendency for developing dry socket than the males.

Smoking is a risk factor which affects the healing of the wound. Studies written by authors Sweet and Butler report that among 400 cases of extracted mandibular third molars, those who smoked a half a pack of cigarettes a day had increased chances of up to five-fold to develop dry socket versus non-smoking patients (12\% vs 6\%) [7]. Dry socket occurrence increases more than $20 \%$ in patients who smoke more than a pack a day, and $40 \%$ in patients who smoke on the day of surgery or the first day after surgery. This phenomenon is likely to appear due to foreign substances which act as contaminants in the wound after tooth extraction, and/or due to the inhalation of cigarette which can decompose and slow down wound healing. This is explained by the destruction of blood clot with smoking and the contamination of the wound by foreign substances [7].

Etiopatogenesis of dry socket is not known but two prevailing theories that try to explain it are the fibrinolytic theory of BIRN and bacterial theory. According to the fibrinolytic theory, after tooth extraction, an inflammatory process starts which will affect the formation and preservation of blood clot [8]. In patients which develop dry socket, bacterial theory is based on the existence of the high presence of bacteria ,before and after tooth extraction, versus a less bacterial environment in other patients who do not develop dry socket [9]. This theory supports the occurrence of higher incidence of dry socket in patients with poor oral hygiene more [10], or in those with pericoronitis or simultaneous periodontal disease [11].

\section{Purpose of Study}

The purpose of this paper is to prove the theory of presence of bacterial dry socket after extraction of the third mandibule molar and exploring the effectiveness of using local-intraalveolare Climdamycin to cover the wound and to avoid systemic use. Bacteria, particularly anaerobic are the main cause of alveolitis and research has shown the presence of such bacteria as streptococci, fusospirochaetal, treponema denticola, and Bacteroides.

\section{Materials and Methods}

In this study, two groups of 30 patients were formed. The first group of patients included nonsmokers while the second group was smokers. In both groups, the third molar of the lower jaw was removed on both sides simultaneously. On the left side of the alveolus the wound was packed with Clindamycin and sutured. On the right side, the wound is sutured without being packed with Clindamycin. The left sides served as research while the right side as control, allowing having both features in the same patient of the same category.

Criteria for including patients in the research

In this prospective clinical study, patients were included according to the indication for removal of third molar mandible on the left and right side. Patients were categorized into two groups: smokers and non-smokers.

Criteria for not including patients in the research

Patients with health problems such as acute and chronic cardio-vascular system, pulmonary, gastrointestinal system or metabolic disease, renal insufficiency, possible allergies (especially in Clindamycin) pregnant woman or still breastfeeding, and patients during the menstrual cycle were excluded from the study. Also excluded from the study were patients that received antibiotic therapy 14 days prior to extraction.

Each patient received a thorough check (history), clinical examination was done as well as complete medical history-information on the consumption of tobacco, correct examination of the oral cavity in order to obtain dental status, and additional examination-Rtg.

Then, the following was then done:

1) Categorization of patients: smokers and non-smokers, age and gender.

2) Application of local anesthetic, lidocaine with $2 \%$ adrenaline. We applied IANB-intra alveolar nerve block 
in order to achieve proper anesthetic effect and to remove local stronger effect of vasoconstrictor to the extraction zone.

3) Extraction of the tooth.

4) Preparing Clindamycin: capsules of $300 \mathrm{mg}$ Clindamycin (manufacturer-LEK-Ljubljana) opened in a sterile container and mixed with $0.2 \mathrm{ml}$ of saliva, then is immersed in Gelatamp-Hemostatic sponge (ROEKO-resorptiv drug for treatment after tooth extraction with excellent compatibility that protects blood clot and wound healing).

5) Local application of Clindamycin on one extraction socket on the left side and then sutured while the opposite side is sutured without the application of Clindamycin.

6) Patients were assigned the following guidelines:

- to not eat or drink until the effects of the anesthetics fades;

- soft and cold food can be consumed after 2 hours while being very careful of not hurting the wound;

- to not rinse the mouth for the next 24 hours following the extraction;

- cold presses to be held on the outside of the jaw for 24 hours;

- analgetic medication to be taken only in case of dolor post extractionem and to specify which side the dolor post extractionem is coming from.

7) Patients were appointed on the first day, the second and the fifth day after the intervention to assess the possible presence of dry socket and post extraction pain.

8) Data were recorded in separate cartons to prepare for research.

9) Statistical analysis of data.

Data processing was done with the statistical package Instat 3. Obtained data are presented in tables. Statistical parameters were calculated from the arithmetic mean, standard deviation, median, minimum and maximum values. Data quality testing is done with the $\mathrm{X}^{2}$-test and Fisher's exact test and quantitative data that have a normal distribution with T-test, and when they did not have a normal distribution with the Mann Whitney test. Verification of tests was made with 99.7\% confidence level $(\mathrm{p}<0.01)$ and the reliability of $95 \%(\mathrm{p}<0.05)$.

\section{Results}

In patients who were smoker and we apply Clindamycin, dry socket were present in $1 \%$ or $3.3 \%$ of cases. Dry socket didn't have $95.2 \%$ female and $100.0 \%$ in male. There was no statistically significant deference according to gender $(\mathrm{p}>0.05)$ (Table 1$)$.

In patients who were smoker and we didn't apply Clindamycin, dry socket were present in $13 \%$ or $43.3 \%$ of cases. Dry socket didn't show in $47.6 \%$ in female and $77.8 \%$ cases of male. There was no statistically significant deference according to gender ( $\mathrm{p}>0.05$ ) (Table 2).

In non smoker patient were we apply Clindamycin, dry socket was present in $1 \%$ or $3.3 \%$ cases. In female there was no dry socket and in male $5.6 \%$ of cases. There was no statistically significant deference according to gender $(\mathrm{p}>0.05)$ (Table 3$)$.

In non smoker patient were we didn’t apply Clindamycin dry socket was present $6 \%$ or $20.0 \%$ cases. Dry socket was present in $16.7 \%$ female cases sand $22.2 \%$ male cases There was no statistically significant deference according to gender ( $\mathrm{p}>0.05)$ (Table 4).

In patiens who were smoker and we apply Clindamycin dry socket appeared in $1 \%$ or $3.3 \%$ cases and in patiens who were smokers and we didn't apply clyndamycin dry socket appeared in $13 \%$ or $43.3 \%$ of cases. There was statistically significant $(\mathrm{p}=0.0004, \mathrm{p}<0.01)$ (Table 5).

In non smoker patient in which we apply Clindamycin, dry socket appears in $1 \%$ or $3.3 \%$ cases and in non smoker patient in which we didn't apply Clindamycin, dry socket appears in $6 \%$ or $20.0 \%$ cases. There was no statistically significant deference $(p=0.102, p>0.05)$ (Table 6).

In smoker patient in which we apply Clindamycin, dry socket appears in $1 \%$ or $3.3 \%$ cases and in non smoker patient in which we did apply Clindamycin ,dry socket appears in 1 or $3.3 \%$ cases. There was no statistically significant deference $(\mathrm{p}>0.05)$ (Table 7).

In smoker patient in which we didn't apply Clindamycin dry socket appears in $13 \%$ or $43.3 \%$ cases and in non smoker patient in which we didn't apply Clindamycin dry socket appears $6 \%$ or $20.0 \%$. There was no statistically significant deference $(\mathrm{p}>0.05)$ (Table 8).

In case when we apply Clindamycin no matter is he a smoker or not, dry socket appears in $2 \%$ or $3.3 \%$ cases In case when we didn't apply Clindamycin no matter is he a smoker or not, dry socket appears in $19 \%$ or $31.7 \%$. There was statistically significant deference $(\mathrm{p}<0.0001)$ (Table 9). 
Table 1. Dry socket in smokers group with Clindamycin application according to gender.

\begin{tabular}{|c|c|c|c|c|c|c|}
\hline \multirow{4}{*}{ Dry Socket } & \multicolumn{4}{|c|}{ Smokers with Clindamycin } & \multirow{2}{*}{\multicolumn{2}{|c|}{ Total }} \\
\hline & \multicolumn{4}{|c|}{ Gender } & & \\
\hline & \multicolumn{2}{|c|}{$\mathrm{F}$} & \multicolumn{2}{|c|}{ M } & \multirow[b]{2}{*}{$\mathrm{N}$} & \multirow[b]{2}{*}{$\%$} \\
\hline & $\mathrm{N}$ & $\%$ & $\mathrm{~N}$ & $\%$ & & \\
\hline Yes & 1 & 4.8 & - & - & 1 & 3.3 \\
\hline No & 20 & 95.2 & 9 & 100.0 & 29 & 96.7 \\
\hline Total & 21 & 100.0 & 9 & 100.0 & 30 & 100.0 \\
\hline Fisher Test & \multicolumn{4}{|c|}{$p=1.00$} & & \\
\hline
\end{tabular}

Table 2. Dry socket in smokers group without Clindamycin application according to gender.

\begin{tabular}{|c|c|c|c|c|c|c|}
\hline \multirow{4}{*}{ Dry Socket } & \multicolumn{4}{|c|}{ Smokers without } & \multirow{2}{*}{\multicolumn{2}{|c|}{ Total }} \\
\hline & \multicolumn{4}{|c|}{ Clindamycin } & & \\
\hline & \multicolumn{2}{|c|}{$\mathrm{F}$} & \multicolumn{2}{|c|}{ M } & \multirow[b]{2}{*}{$\mathrm{N}$} & \multirow[b]{2}{*}{$\%$} \\
\hline & $\mathrm{N}$ & $\%$ & $\mathrm{~N}$ & $\%$ & & \\
\hline Yes & 11 & 52.4 & 2 & 22.2 & 13 & 43.3 \\
\hline No & 10 & 47.6 & 7 & 77.8 & 17 & 56.7 \\
\hline Total & 21 & 100.0 & 9 & 100.0 & 30 & 100.0 \\
\hline Fisher Test & \multicolumn{4}{|c|}{$p=0.229$} & & \\
\hline
\end{tabular}

Table 3. Dry socket in non smoker group with Clindamycin according to gender.

\begin{tabular}{|c|c|c|c|c|c|c|}
\hline \multirow{4}{*}{ Dry Socket } & \multicolumn{4}{|c|}{ Non Smoker with Clindamycin } & & \\
\hline & \multicolumn{4}{|c|}{ Gender } & \multicolumn{2}{|c|}{ Total } \\
\hline & \multicolumn{2}{|c|}{ F } & \multicolumn{2}{|c|}{ M } & \multirow[b]{2}{*}{$\mathrm{N}$} & \multirow[b]{2}{*}{$\%$} \\
\hline & $\mathrm{N}$ & $\%$ & $\mathrm{~N}$ & $\%$ & & \\
\hline Yes & - & - & 1 & 5.6 & 1 & 3.3 \\
\hline No & 12 & 100.0 & 17 & 94.4 & 29 & 96.7 \\
\hline Total & 12 & 100.0 & 18 & 100.0 & 30 & 100.0 \\
\hline Fisher Test & \multicolumn{4}{|c|}{$\mathrm{p}=1.00$} & & \\
\hline
\end{tabular}

Table 4. Dry socket in non smoker group without Clindamycin according to gender.

\begin{tabular}{|c|c|c|c|c|c|c|}
\hline \multirow{4}{*}{ Dry Socket } & \multicolumn{4}{|c|}{ Non Smoker without Clindamycin } & \multirow{2}{*}{\multicolumn{2}{|c|}{ Total }} \\
\hline & \multicolumn{4}{|c|}{ Gender } & & \\
\hline & \multicolumn{2}{|c|}{$\mathrm{F}$} & \multicolumn{2}{|c|}{ M } & \multirow[b]{2}{*}{$\mathrm{N}$} & \multirow[b]{2}{*}{$\%$} \\
\hline & $\mathrm{N}$ & $\%$ & $\mathrm{~N}$ & $\%$ & & \\
\hline Yes & 2 & 16.7 & 4 & 22.2 & 6 & 20.0 \\
\hline No & 10 & 83.3 & 14 & 77.8 & 24 & 80.0 \\
\hline Total & 12 & 100.0 & 18 & 100.0 & 30 & 100.0 \\
\hline Fisher Test & \multicolumn{4}{|c|}{$\mathrm{p}=1.00$} & & \\
\hline
\end{tabular}


Table 5. Dry socket in smokers depending on use of Clindamycin.

\begin{tabular}{|c|c|c|c|c|}
\hline \multirow{2}{*}{ Dry Socket } & \multicolumn{2}{|c|}{ Smokers Clindamycin } & \multicolumn{2}{|c|}{ Smokers without Clindamycin } \\
\hline & $\mathrm{N}$ & $\%$ & $\mathrm{~N}$ & $\%$ \\
\hline Yes & 1 & 3.3 & 13 & 43.3 \\
\hline No & 29 & 96.7 & 17 & 56.7 \\
\hline Total & 30 & 100.0 & 30 & 100.0 \\
\hline Fisher Test & \multicolumn{4}{|c|}{$p=0.0004$} \\
\hline
\end{tabular}

Table 6. Dry socket in non smokers depending on application of Clindamycin.

\begin{tabular}{ccccc}
\hline & \multicolumn{2}{c}{ Non Smokers with Clindamycin } & \multicolumn{2}{c}{ Non Smokers without Clindamycin } \\
\cline { 2 - 5 } Dry Socket & $\mathrm{N}$ & $\%$ & $\mathrm{~N}$ & $\%$ \\
\hline Yes & 1 & 3.3 & 6 & 20.0 \\
No & 29 & 96.7 & 30 & 100.0 \\
Total & 30 & 100.0 & $\mathrm{p}=0.102$ & \\
Fisher Test & & & & \\
\hline
\end{tabular}

Table 7. Dry socket in smokes depending on application of Clindamycin.

\begin{tabular}{|c|c|c|c|c|}
\hline \multirow{2}{*}{ Dry Socket } & \multicolumn{2}{|c|}{ Smokers with Clindamycin } & \multicolumn{2}{|c|}{ Non Smokers with Clindamycin } \\
\hline & $\mathrm{N}$ & $\%$ & $\mathrm{~N}$ & $\%$ \\
\hline Yes & 1 & 3.3 & 1 & 3.3 \\
\hline No & 29 & 96.7 & 29 & 96.7 \\
\hline Total & 30 & 100.0 & 30 & 100.0 \\
\hline Fisher Test & \multicolumn{4}{|c|}{$\mathrm{p}=1.00$} \\
\hline
\end{tabular}

Table 8. Dry socket in patient without Clindamycin depending on smoking.

\begin{tabular}{ccccc}
\hline & \multicolumn{2}{c}{ Smoker without Clindamycin } & \multicolumn{2}{c}{ Non Smoker without Clindamycin } \\
\cline { 2 - 5 } Dry Socket & $\mathrm{N}$ & $\%$ & $\mathrm{~N}$ & $\%$ \\
\hline Yes & 13 & 43.3 & 6 & 20.0 \\
No & 17 & 56.7 & 24 & 80.0 \\
Total & 30 & 100.0 & 30 & 100.0 \\
Fisher Test & & & $\mathrm{p}=0.094$ & \\
\hline
\end{tabular}

Table 9. Dry socket depending on placement of Clindamycin.

\begin{tabular}{|c|c|c|c|c|c|c|}
\hline \multirow{3}{*}{ Dry Socket } & \multicolumn{4}{|c|}{ Clindamycin } & \multirow{2}{*}{\multicolumn{2}{|c|}{ Total }} \\
\hline & \multicolumn{2}{|c|}{ Yes } & \multicolumn{2}{|c|}{ No } & & \\
\hline & $\mathrm{N}$ & $\%$ & $\mathrm{~N}$ & $\%$ & $\mathrm{~N}$ & $\%$ \\
\hline Po & 2 & 3.3 & 19 & 31.7 & 21 & 17.5 \\
\hline Jo & 58 & 96.7 & 41 & 68.3 & 99 & 82.5 \\
\hline Total & 60 & 100.0 & 60 & 100.0 & 120 & 100.0 \\
\hline Fisher Test & & & & & & \\
\hline
\end{tabular}




\section{Discussion}

Clindamycin is known to have a very favorable spectrum of activity against anaerobic infections [12] [13]. Its antimicrobial spectrum also includes Gram-positive cocci, Gram-positive and -negative anaerobes and certain protozoa [14]. Although classed as bacteriostatic, bactericidal activity is usually achieved with the recommended doses [15]. The mechanism of action of Clindamycin is by the inhibition of protein synthesis, acting specifically on the 50S subunit of the bacterial ribosome. Protein synthesis is inhibited primarily in early chain elongation by interference with the transpeptidation reaction [15]. Clindamycin is the drug of choice in the prevention of dry socket due to anaerobic properties [16] [17].

A number of clinical trials have demonstrated Clindamycin's efficacy in treating odontogenic infections. Three studies reported comparable findings when Clindamycin was compared with penicillin for the management of orofacial infections [17]-[21]. All three concluded that Clindamycin would be a suitable alternative to penicillin. In a recent study into the bacteriological features and antimicrobial susceptibilities of bacteria isolated from orofacialodontogenic infections, penicillin was found to be effective against most major pathogens involved [20]. Although Clindamycin was also found to be a suitable agent, it was suggested that Clindamycin be reserved for those cases in which penicillin therapy had failed.

No single factor could be regarded as a cause for development of dry socket as a complication after extraction of third mandibular tooth. However, in this study we investigate the indication of local applied Clindamycin to reduce dry socket. Regarding gender, the majority of authors support the indication even in females who do not take oral contraceptive who are known to have a greater tendency for developing dry sockets. According to the Amaratunga [22], incidence of alveolitis by gender in female:male is 2:1.

According to Chapnick \& Diamond [23], this double blind clinical study was undertaken to evaluate the effectiveness of locally applied Clindamycin in Gelfoam in reducing the incidence of dry socket formation after third molar surgery. The results indicated that this technique was effective. This study also demonstrates that the incidence of dry socket after third molar surgery is significantly higher in the mandible than the maxilla, in smokers than in non-smokers, and in females currently on oral contraceptives.

In a study done by Kupfer, S.R. [24] Clindamycin and other agents were compared for efficacy in preventing the entity "dry socket”. A total of 765 patients were treated with Clindamycin, per os, and 408 patients were treated with other antibiotics or untreated controls. All patients underwent surgical removal of impacted mandibular third molars. The incidence of dry socket in untreated control and in Non-Clindamycin antibiotic-treated patients varied from $15 \%$ to $31 \%$, while in those patients receiving Clindamycin, the incidence was 0.65 percent. The results demonstrate a remarkable effectiveness of Clindamycin in reducing the incidence of dry socket following surgical removal of impacted mandibular third molar.

\section{Conclusion}

Clindamycin has good antimicrobial properties for the management of most dentoalveolar infections. It includes a favorable spectrum of activity against anaerobic infections and the ability to have a high concentration in bones. It would be worthwhile to see if they could do further clinical studies to verify the hypotheses of dry socket prevention. The more we avoid systematic use of antibiotics the better it is. In this study we concluded that in cases when we apply Clindamycin, regardless of the patient being a smoker or not, dry socket appears in only 3.3\% cases. In cases when we didn’t apply Clindamycin, again regardless of the patient being a smoker or not, dry socket appears in $31.7 \%$. This showed a statistical significant difference $(\mathrm{p}<0.0001)$. As a result, we strongly recommend the use of local intraalvolar Clindamycin after a removal of third mandibular molar. This will improve the patients' quality of life by reducing the chances of developing dry socket which is known to be a very painful experience.

\section{References}

[1] Todorovic, L. (2002) Oralna Hirurgija. Nauka, Beograd.

[2] Testa, D. (2006) AAOMS. Annual Meeting of American Association of Oral and Maxillofacial Surgeons, The Academy of Dental Therapeutics and Stomatology, 5-9.

[3] Barclay, J.K. (1987) Metronidazol and Dry Socket: Profilactic Use in Mandibular Third Molar Removalcomplicated by Non-Acute Pericoronitis. The New Zealand Dental Journal, 7, 71-75. 
[4] Fridrich, K.L. and Olson, R.A.J. (1990) Alveolar Osteitis Following Removal of Mandibular Third Molars. Anesthesia Progress, 37, 32-41.

[5] Rozanis, J., Schofield, I.D.F. and Warren, B.A. (1977) Is Dry Socket Preventable? Journal of the Canadian Dental Association, 43, 223-236.

[6] Akota, I., Alvsaker, B. and Bjornland, T. (1998) The Effect of Locally Applied Gauze Drain Impregnated with Chlortetracycline Ointment in Mandibular Third Molar Surgery. Acta Odontologica Scandinavica, 56, 25-29.

[7] Sweet, J.B. and Butler, D.P. (1979) The Relationship of Smoking to Localized Osteitis. Journal of Oral Surgery, 37, 732-735.

[8] Birn, H. (1970) Bacterial and Fibrinolytic Activity in “Dry Socket”. Acta Odontologica Scandinavica, 28, $773-783$. http://dx.doi.org/10.3109/00016357009028246

[9] Torres-Lagares, D., Serrera-Figallo, M.A., Romero-Ruíz, M.M., Infante-Cossío, P., García-Calderón, M. and GutiérrezPérez, J.L. (2005) Alveolitis Seca. Actualización de Conceptos. Medicina Oral, Patología Oral y Cirugía Bucal, 10, 77-85.

[10] Meechan, J.G., Venchard, G.R. and Rogers, S.N. (1987) Local Anesthesia and Dry Socket: A Clinical Investigation of Single Extractions in Male Patients. International Journal of Oral and Maxillofacial Surgery, 16, 279-284. http://dx.doi.org/10.1016/S0901-5027(87)80148-0

[11] Ritzau, M., Hillerub, S., Branebjerg, P.E. and Eersbol, B.K. (1992) Does Metronidazole Prevent Alveolitis Sicca Dolorsa? A Double-Blind, Placebo-Controlled Clinical Study. International Journal of Oral and Maxillofacial Surgery, 21, 299-302. http://dx.doi.org/10.1016/S0901-5027(05)80743-X

[12] von Konow, L., Nord, C.E. and Nordenram, A. (1981) Anaerobic Bacteria in Dentoalveolar Infections. International Journal of Oral Surgery, 10, 313-322.

[13] Phillips, L., Fernandes, R. and Warren, C. (1970) In-Vitro Comparison of Erythromycin, Lincomycin, and Clindamycin. British Medical Journal, 2, 89-90. http://dx.doi.org/10.1136/bmj.2.5701.89

[14] Dhawan, V.K. and Thadepalli, H. (1982) Clindamycin: A Review of Fifteen Years of Experience. Clinical Infectious Diseases, 4, 1133-1153. http://dx.doi.org/10.1093/clinids/4.6.1133

[15] Steigbigel, N. (1995) Macrolides and Clindamycin. In: Mandell, Douglas and Bennett's Principles and Practice of Infectious Diseases, 4th Edition, Churchill Livingstone, New York, 366-382.

[16] Rud, J. (1970) Removal of Impacted Lower Third Molars with Acute Pericoronitis and Necrotizing Gingivitis. British Journal of Oral Surgery, 7, 153-160. http://dx.doi.org/10.1016/s0007-117x(69)80015-6

[17] Larsen, P.E. (1991) The Effect of a Chlorhexidine Rinse on the Incidence of Alveolar Osteitis Following the Surgical Removal of Impacted Mandibular Third Molar. Journal of Oral and Maxillofacial Surgery, 49, 932-937.

[18] Schuen, N.J., Panzer, J.D. and Atkinson, W.H. (1974) A Comparison of Clindamycin and Penicillin V in the Treatment of Oral Infections. Journal of Oral Surgery, 32, 503-505.

[19] Gilmore, W.C., Jacobus, N.V., Gorbach, S.L., Doku, H.C. and Tally, F.P. (1988) A Prospective Double-Blind Evaluation of Penicillin versus Clindamycin in the Treatment of Odontogenic Infections. Journal of Oral and Maxillofacial Surgery, 46, 1065-1070. http://dx.doi.org/10.1016/0278-2391(88)90452-1

[20] Kannangara, D.W., Thadepalli, H. and McQuirter, J.L. (1980) Bacteriology and Treatment of Dental Infections. Oral Surgery, Oral Medicine, Oral Pathology, 50, 103-109. http://dx.doi.org/10.1016/0030-4220(80)90194-2

[21] Kuriyama, T., Karasawa, T., Nakagawa, K., Saiki, Y., Yamamoto, E. and Nakamura, S. (2000) Bacteriologic Features and Antimicrobial Susceptibility in Isolates from Orofacial Odontogenic Infections. Oral Surgery, Oral Medicine, Oral Pathology, Oral Radiology and Endodontics, 90, 600-608. http://dx.doi.org/10.1067/moe.2000.109639

[22] Amaratunga, N.A. and Senaratne, C.M. (1988) A Clinical Study of Dry Socket in Sri Lanka. British Journal of Oral and Maxillofacial Surgery, 26, 410-418. http://dx.doi.org/10.1016/0266-4356(88)90094-0

[23] Chapnick, P. and Diamond, L. (1992) A Review of Dry Socket: A Double-Blind Study on the Effectiveness of Clindamycin in Reducing the Incidence of Dry Socket. Journal of the Canadian Dental Association, 58, 43-52.

[24] Kupfer, S.R. (1995) Prevention of Dry Socket with Clindamycin. A Retrospective Study. New York State Dental Journal, 61, 30-33. 
Scientific Research Publishing (SCIRP) is one of the largest Open Access journal publishers. It is currently publishing more than 200 open access, online, peer-reviewed journals covering a wide range of academic disciplines. SCIRP serves the worldwide academic communities and contributes to the progress and application of science with its publication.

Other selected journals from SCIRP are listed as below. Submit your manuscript to us via either submit@scirp.org or Online Submission Portal.
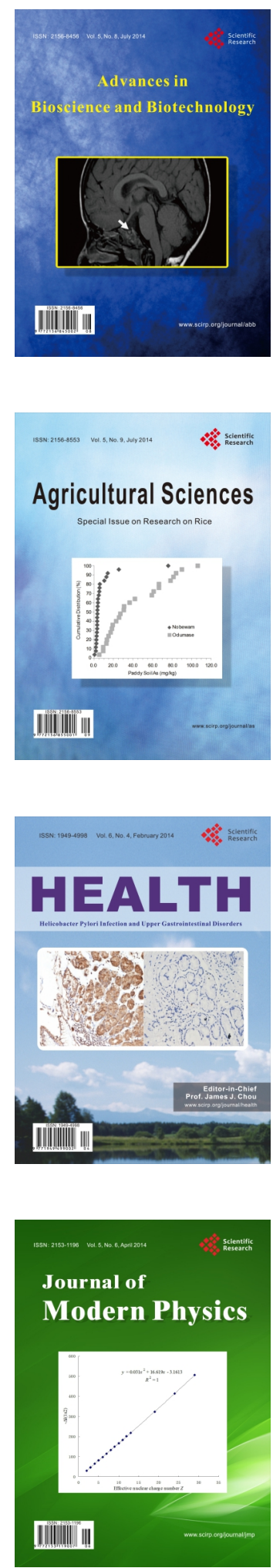
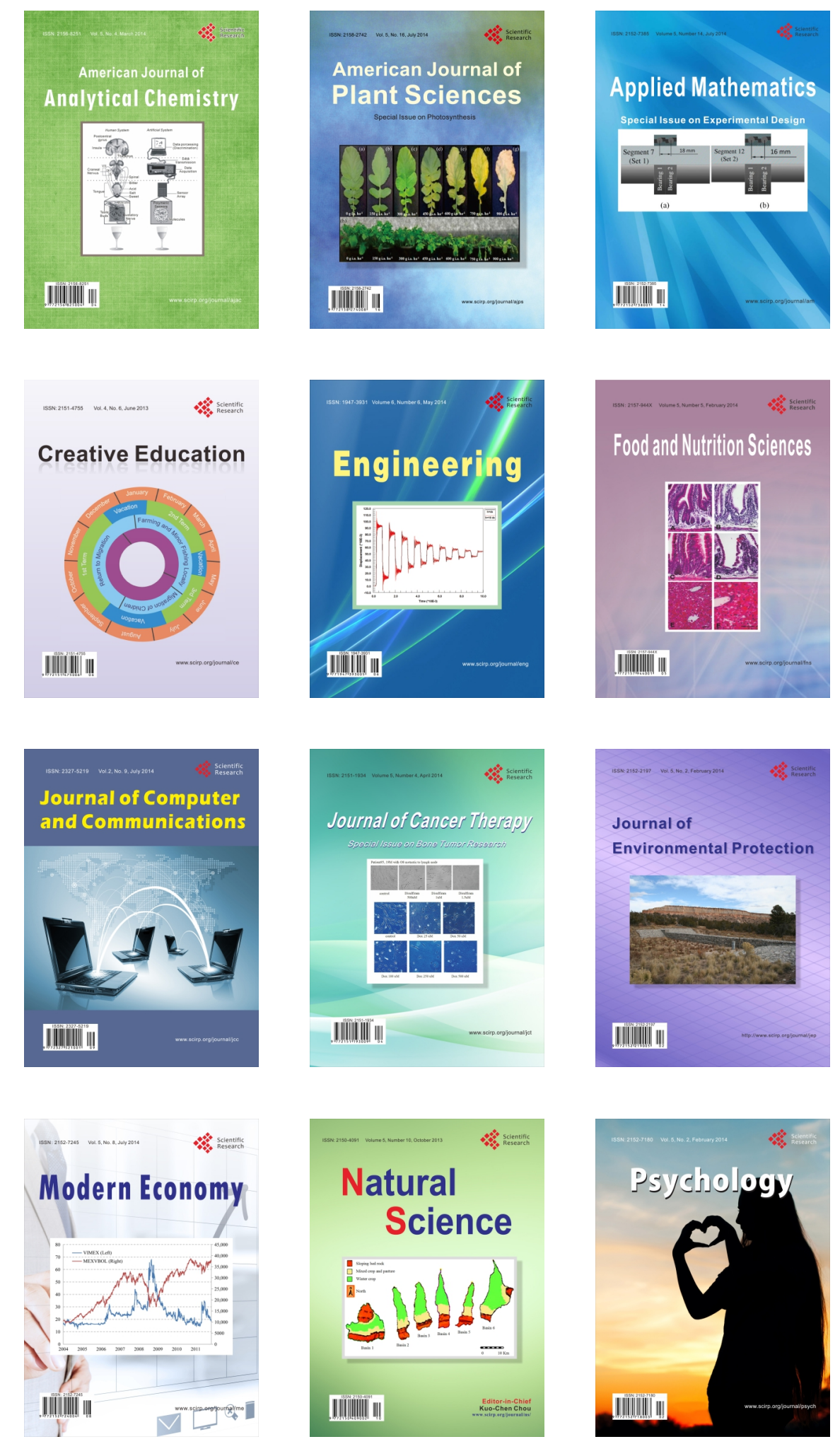